\title{
Subpicosecond dynamics in DNA from leaves of in vitro-grown apple plants: A SERS study
}

\author{
Cristina M. Muntean ${ }^{\mathrm{a}, *}$, Ioan Bratu ${ }^{\mathrm{a}}$, Nicolae Leopold ${ }^{\mathrm{b}}$ and Monica A.P. Purcaru ${ }^{\mathrm{c}}$ \\ ${ }^{\mathrm{a}}$ National Institute for Research and Development of Isotopic and Molecular Technologies, \\ Cluj-Napoca, Romania \\ ${ }^{\mathrm{b}}$ Babes-Bolyai University, Faculty of Physics, Cluj-Napoca, Romania \\ ${ }^{\mathrm{c}}$ Transilvania University of Brasov, Brasov, Romania
}

\begin{abstract}
In this work the SERS total half bandwidths of five genomic DNAs from in vitro-grown apple leaf tissues (Malus domestica Borkh., Fam Rosaceae, cvs. Florina, Rebra, Goldrush, Romus 3 and Romus 4) have been measured. We have shown that surface-enhanced Raman scattering can be used to study the fast subpicosecond dynamics of DNA in the proximity of a metallic surface. The dependencies of the total half bandwidths and of the global relaxation times, on DNA molecular subgroup structure, on the type of genomic apple plant DNA and on time, are reported. An example of the time-dependence of SERS band parameters of DNA, in the proximity of silver nanoparticles, has been given. It is shown that changes in the subpicosecond surface dynamics of molecular subgroups in genomic DNAs from in vitro-grown apple leaf tissues can be monitored with surface-enhanced Raman spectroscopy.

Particularly, the SERS band parameters for the vibrations near $757 \mathrm{~cm}^{-1}$ (dT), $773 \mathrm{~cm}^{-1}$ (dC), $929 \mathrm{~cm}^{-1}$ (deoxyribose), $1087 \mathrm{~cm}^{-1}\left(\mathrm{PO}_{2}{ }^{-}\right.$symmetric stretch, backbone), $1127 \mathrm{~cm}^{-1}(\mathrm{dA}), 1181 \mathrm{~cm}^{-1}$ (ring vibrations of dG, dT, dC), $1311 \mathrm{~cm}^{-1}$ (dA), $1362 \mathrm{~cm}^{-1}(\mathrm{dT}, \mathrm{dA}), 1510 \mathrm{~cm}^{-1}(\mathrm{dA}), 1573 \mathrm{~cm}^{-1}(\mathrm{dG}, \mathrm{dA})$ and $1650 \mathrm{~cm}^{-1}$ [dT(C=O), $\left.\delta\left(\mathrm{H}_{2} \mathrm{O}\right)\right]$ of genomic DNAs from apple leaves are presented. In our study, the full widths at half-maximum (FWHM) of the bands in genomic DNAs from in vitro-grown apple leaf tissues are typically in the wavenumber range from 14 to $52 \mathrm{~cm}^{-1}$. Besides, it can be observed that molecular relaxation processes studied in this work, have a global relaxation time smaller than $0.76 \mathrm{ps}$ and larger than $0.20 \mathrm{ps}$.

A comparison between different ranges of FT-Raman and SERS band parameters of DNA extracted from leaf tissues, respectively, is given.

We have found that the bands of DNA from Romus 3 and Rebra cultivars are suitable for studying the dynamical behaviour of molecular subgroups, in genomic nucleic acids extracted from in vitro-grown apple plants.
\end{abstract}

Keywords: Genomic DNA, in vitro-grown apple leaf tissues, surface-enhanced Raman scattering, full widths at half-maximum, subpicosecond global relaxation time, time-dependence of the SERS band parameters

\section{Introduction}

Biological world is one of perpetual movement, a fundamental characteristic of life. The dynamics of macromolecules is thus a fundamental component of their behaviour. It is well known that the dynamics of biopolymers occurs on a wide range of time scales, extending from seconds to femtoseconds [20].

\footnotetext{
${ }^{*}$ Corresponding author: Dr. Cristina M. Muntean, National Institute for Research and Development of Isotopic and Molecular Technologies, P.O. 5, Box 700, R-400293 Cluj-Napoca, Romania. E-mail: cmuntean@itim-cj.ro.
} 
Particularly, studies of molecular relaxations in liquids are valuable in providing information about the intermolecular interaction processes in condensed matter [4]. Raman and infrared spectroscopies offer the most significant information concerning the behaviour of a condensed system in the picosecond timescale [3].

Among the techniques available for the study of molecular motions in liquids, Raman scattering has the distinct advantage, that it enables simultaneous analyses of both reorientational and vibrational processes $([3,4,8,9]$ and references therein).

Particularly, vibrational relaxation plays a crucial role in many aspects of chemistry, physics and biology $([1,10]$ and references therein). A number of dynamical processes which have been considered to broaden the vibrational bands of nucleic acids in the frequency domain, are: vibrational resonance coupling, vibrational energy exchange, vibrational dephasing and rotational broadening $([7,19]$ and references therein).

The biopolymer motion in fluids is generally too slow to be observed in the Raman time window that is accessible in the frequency domain. On contrary, the motion of molecular subgroups can be fast enough $[9,16]$. Different vibrational modes of a DNA molecule can behave quite different, upon changing the structure of nucleic acid by varying the $\mathrm{pH}$ or by the presence of proteins, metal ions and intercalators in the system $[6,7,9,15]$.

A confocal Raman microspectroscopic study into the vibrational half bandwidths of molecular subgroups in calf-thymus DNA at $\mathrm{pH} 7$ and $\mathrm{pH} 3$, in the presence of $\mathrm{Na}^{+}, \mathrm{Ca}^{2+}$ and $\mathrm{Mg}^{2+}$ ions, respectively, was previously reported by us [6]. The bandwidths in the Raman spectra were sensitive to a dynamics active on a time scale ranging from 0.34 to 1.44 ps $[6,8,9]$.

Also, the dependencies of the full widths at half-maximum (FWHM) and of the global relaxation times on DNA molecular subgroup structure and on $\mathrm{pH}$ values, in the presence of $\mathrm{Mn}^{2+}$ ions, have been studied [8].

Molecular relaxation processes in calf-thymus DNA, in the presence of different concentrations of $\mathrm{Mn}^{2+}$ and $\mathrm{Na}^{+}$ions, respectively, were investigated by Raman spectroscopy $[7,13,14]$. The fullwidths at half-height (FWHH) of the bands in DNA were typically in the wavenumber range from 9 to $33.5 \mathrm{~cm}^{-1}$. It could be observed that the molecular dynamics studied in this work, was characterized by a global relaxation time smaller than $1.18 \mathrm{ps}$ and larger than $0.32 \mathrm{ps}$ [7].

Also the subpicosecond dynamics of DNA subgroups, as a function of $\mathrm{Zn}^{2+}$ ions concentration [10] was presented. Monitoring the changes in the Raman full widths at half-maximum (FWHM) and, correspondingly, in the global relaxation times of the molecular subgroups in DNA, upon varying the $\mathrm{Zn}^{2+}$ concentration, was of interest. It could be observed that the molecular relaxation processes studied in this work, had a global relaxation time smaller than $0.94 \mathrm{ps}$ and larger than $0.21 \mathrm{ps} \mathrm{[10].}$

In the study of nucleic acids, phosphate groups are particularly very important in the structure, dynamics and interactions of mono- and polynucleotides $[2,7,18]$. A study of the dynamics of the $\mathrm{PO}_{3}{ }^{2-}$ group in aqueous solution can give information on the mononucleotide mobility and interactions in its natural solvent $[2,8]$.

Also, vibrational relaxation after spectrally selective excitation within the $\mathrm{NH}$ stretching band of adenine-thymine base pairs, in DNA oligomers, was studied by subpicosecond infrared-pump/antiStokes Raman-probe spectroscopy [5].

In this paper the SERS total half bandwidths of five genomic DNAs from in vitro-grown apple leaf tissues (Malus domestica Borkh., Fam Rosaceae, cvs. Florina, Rebra, Goldrush, Romus 3 and Romus 4) have been measured. 
The dependencies of the total half bandwidths and of the global relaxation times, on DNA molecular subgroup structure, on the type of genomic apple plant DNA, and on time are reported.

It is shown that changes in the subpicosecond dynamics of molecular subgroups in genomic DNAs from in vitro-grown apple leaf tissues, in the proximity of a silver surface, can be monitored with surfaceenhanced Raman spectroscopy (SERS).

Previously, a FT-Raman study of the (sub)picoseconds dynamics in genomic DNA from plant tissues was also done by us [4] and is used for comparison in the present work.

\section{Experimental section}

The experimental details of the SERS spectra, obtained for genomic DNA from different in vitrogrown apple plant tissues, were given in [12]. Leaves from in vitro-grown apple plants of different cultivars, were the source material for the extraction of genomic DNAs. These fully expanded leaves were obtained from plants of: Malus domestica Borkh., Fam Rosaceae, cvs. Florina, Rebra, Goldrush, Romus 3 and Romus 4 [12].

SERS spectra were recorded at room temperature, using a DeltaNu Advantage spectrometer (DeltaNu, Laramie, WY) equipped with a doubled frequency Nd:YAG laser, emitting at $532 \mathrm{~nm}$ and $45 \mathrm{~mW}$ laser power. These data are presented elsewhere [12]. Later on the SERS measurements were repeated using the same DNAs and silver colloid system (data not shown).

The band parameters (full widths at half-maximum-FWHMs and global relaxation times) were determined for both data sets.

For each band profile, an individual baseline was taken into account. FWHM of the bands were obtained using SpectraCalc software. The FWHMs were evaluated from the half maximum SERS bands.

\section{Results and discussions}

Relating to molecular relaxation processes, Rakov developed one of the well-known procedures of obtaining the relaxation times and the activation energy [6-10,17].

In this approximation, the total half bandwidth of the depolarized Raman lines contains, two contributions [6-9]:

- an intrinsic bandwidth, $\delta_{0}$, considered temperature independent in that time;

- another contribution $\Delta(T)$ which is temperature dependent.

The total half bandwidth can be written as:

$$
\Delta \nu_{1 / 2}=\delta_{0}+\Delta(T)=\delta_{0}+\frac{1}{\pi c \tau_{r}} .
$$

The potential barrier against reorientation can be obtained as:

$$
\tau_{r}=\tau_{0} \exp \left(\frac{U_{o r}}{k T}\right)
$$

where $\tau_{0}$ is the period of the molecule oscillation around the equilibrium position, and $U_{o r}$ is the energy barrier or the activation energy $[6,7,10]$. 
The Rakov relationship can be written as:

$$
\Delta \nu_{1 / 2}=\delta_{0}+\frac{1}{\pi c \tau_{0}} \exp \left(\frac{-U_{o r}}{k T}\right)
$$

From the $\left(\Delta \nu_{1 / 2}-\delta_{0}\right)$ vs $\frac{10^{3}}{T}$ dependencies one can obtain $U_{o r}$ as the slope of this linear dependence [6-8].

The temperature "independent" part, due to the vibrational relaxation, $\delta_{\mathrm{v}}$, presents small temperature dependence, opposite to the one due to the reorientational relaxation.

For large molecules, in aqueous solutions, the vibrational contribution becomes important. From Raman measurements, using polarized light, it is possible to do the selection of these two contributions $[6,7,10]$. As a first approximation, one can assume, the existence of a global relaxation time, $\tau$, obtained from the total Raman half bandwidth. This band parameter can be related with the intrinsic parameters of the analyzed system through the relationship:

$$
\tau_{v, 1 R, 2 R}=\frac{1}{\pi c \Delta \nu_{1 / 2}^{v, 1 R, 2 R}},
$$

where the half bandwidth includes the vibrational $\left(\Delta \nu_{1 / 2}^{v}\right)$ and rotational $\left(\Delta \nu_{1 / 2}^{1 R, 2 R}\right)$ contributions and $c$ is the velocity of light. $\Delta \nu_{1 / 2}^{1 R, 2 R}$ is obtained from IR and Raman bands, respectively [6-9].

The development of fast and accurate curve fitting programs allows the analysis of the vibrational spectra of complicated biological molecules, containing often more than 40 vibrational bands $([9,19]$ and references therein).

In this paper we will concentrate on the vibrational bandwidths. Only the relatively isolated nucleic acids vibrations will be considered [6,7,9]. A study into the SERS vibrational bandwidths and the corresponding global relaxation times of molecular subgroups in genomic DNA from different in vitro-grown apple leaf tissues, is of interest. Time-dependence of the SERS band parameters characterizing genomic plant DNAs is also analyzed herewith.

For the case of aqueous solutions of DNA molecules, we can suppose that the dominant relaxation mechanism is the vibrational one. The values of the global relaxation time suggest also the existence of a vibrational relaxation time, because the reorientational movement is much more slower for the DNA macromolecule in aqueous solution [7,9]. Particularly, the absence of reorientational broadening in polynucleotides indicates that the bases in polynucleotides reorient through an angle of $41^{\circ}$ in times slower than $21 \mathrm{ps}([8,19]$ and references therein).

As a general rule, the bandwidths in the Raman spectra are sensitive to a dynamics active on a time scale from 0.1 to $10 \mathrm{ps}[7,19]$.

The SERS band parameters for the vibrations near $757 \mathrm{~cm}^{-1}(\mathrm{dT}), 773 \mathrm{~cm}^{-1}(\mathrm{dC}), 929 \mathrm{~cm}^{-1}$ (deoxyribose), $1087 \mathrm{~cm}^{-1}\left(\mathrm{PO}_{2}{ }^{-}\right.$symmetric stretch, backbone), $1127 \mathrm{~cm}^{-1}(\mathrm{dA}), 1181 \mathrm{~cm}^{-1}$ (ring vibrations of dG, dT, dC), $1311 \mathrm{~cm}^{-1}(\mathrm{dA}), 1362 \mathrm{~cm}^{-1}(\mathrm{dT}, \mathrm{dA}), 1510 \mathrm{~cm}^{-1}(\mathrm{dA}), 1573 \mathrm{~cm}^{-1}(\mathrm{dG}, \mathrm{dA})$ and $1650 \mathrm{~cm}^{-1}\left[\mathrm{dT}(\mathrm{C}=\mathrm{O}), \delta\left(\mathrm{H}_{2} \mathrm{O}\right)\right]$ characteristic to genomic DNAs from different in vitro-grown apple leaf tissues are summarized in Tables 1 and 2, respectively ([12] and references therein). Data in Table 2 correspond to the same samples as data in Table 1, but at a time later.

The full widths at half-maximum (FWHM) of the SERS bands in genomic DNAs from different apple leaf tissues, are presented for five samples, each at two different interaction times of DNA with the silver 
Table 1

Total half bandwidths $\left(\mathrm{cm}^{-1}\right)$ of SERS vibrational markers and global relaxation times of molecular subgroups, in genomic DNA from different in vitro-grown apple leaf tissues

\begin{tabular}{|c|c|c|}
\hline$\nu_{\max }\left(\mathrm{cm}^{-1}\right)$ Tentative assignment ${ }^{\mathrm{a}}[12]$ & $\Delta \nu_{1 / 2}\left(\mathrm{~cm}^{-1}\right)$ & $\tau_{\text {SERS }}(\mathrm{ps})$ \\
\hline \multicolumn{3}{|l|}{ Florina } \\
\hline 565 & 23 & 0.46 \\
\hline 614 & 23 & 0.46 \\
\hline $757(\mathrm{dT})$ & $22^{*}$ & 0.48 \\
\hline $1550(\mathrm{dG}, \mathrm{dA})$ & $52^{*}$ & 0.20 \\
\hline \multicolumn{3}{|l|}{ Romus 4} \\
\hline 611 & 15.5 & 0.68 \\
\hline $772(\mathrm{dC})$ & 29 & 0.37 \\
\hline $1512(\mathrm{dA})$ & $30^{*}$ & 0.35 \\
\hline \multicolumn{3}{|l|}{ Romus 3} \\
\hline 611 & 15.5 & 0.68 \\
\hline $772(\mathrm{dC})$ & 23.5 & 0.45 \\
\hline $1126(\mathrm{dA})$ & 20 & 0.54 \\
\hline $1361(\mathrm{dT}, \mathrm{dA})$ & 21 & 0.51 \\
\hline $1511(\mathrm{dA})$ & 24 & 0.44 \\
\hline $1651\left[\mathrm{dT}(\mathrm{C}=\mathrm{O}), \delta\left(\mathrm{H}_{2} \mathrm{O}\right)\right]$ & 22 & 0.48 \\
\hline \multicolumn{3}{|l|}{ Rebra } \\
\hline 611 & 15 & 0.71 \\
\hline $772(\mathrm{dC})$ & 24 & 0.44 \\
\hline 1179 (Ring vibrations of dG, dT, dC) & 23.5 & 0.45 \\
\hline $1361(\mathrm{dT}, \mathrm{dA})$ & 21 & 0.51 \\
\hline $1510(\mathrm{dA})$ & 24 & 0.44 \\
\hline $1651\left[\mathrm{dT}(\mathrm{C}=\mathrm{O}), \delta\left(\mathrm{H}_{2} \mathrm{O}\right)\right]$ & 18 & 0.59 \\
\hline \multicolumn{3}{|l|}{ Goldrush } \\
\hline 565 & 22 & 0.48 \\
\hline 612 & 20 & 0.54 \\
\hline $763(\mathrm{dT})$ & 34 & 0.31 \\
\hline $1127(\mathrm{dA})$ & 14 & 0.76 \\
\hline
\end{tabular}

a Abbreviations: dA - deoxyadenosine; dG - deoxyguanosine; dC - deoxycytidine; dT deoxythymidine. * Low frequency side of the band was red, later on the respective profile was symmetrically analyzed.

colloid. They are typically in the wavenumber range from 14 to $52 \mathrm{~cm}^{-1}$ (see Table 1) and from 14.5 to $24 \mathrm{~cm}^{-1}$ (see Table 2). The limit wavenumber values belong in the second case to Romus 4 . For some wavenumbers, the FWHMs were not possible to be read.

Besides, the global relaxation times were evaluated on the basis of Eq. (4). From the SERS vibrations around $757 \mathrm{~cm}^{-1}, 772 \mathrm{~cm}^{-1}, 1126 \mathrm{~cm}^{-1}, 1179 \mathrm{~cm}^{-1}, 1361 \mathrm{~cm}^{-1}, 1510 \mathrm{~cm}^{-1}, 1550 \mathrm{~cm}^{-1}$ and $1651 \mathrm{~cm}^{-1}$ (see Table 1), it can be observed that the global relaxation times, for molecular subgroups in genomic DNA from different leaf tissues, are slower than $0.20 \mathrm{ps}$ and faster than $0.76 \mathrm{ps}$. The limit values are characterizing the Florina DNA SERS band at $1550 \mathrm{~cm}^{-1}(\mathrm{dG}, \mathrm{dA})$ (global relaxation time $0.20 \mathrm{ps}$ ), and the Goldrush DNA vibration near $1127 \mathrm{~cm}^{-1}$ (dA), respectively (global relaxation time $0.76 \mathrm{ps})$. 
Table 2

Total half bandwidths $\left(\mathrm{cm}^{-1}\right)$ of SERS vibrational markers and global relaxation times of molecular subgroups, in genomic DNA from different in vitro-grown apple leaf tissues

\begin{tabular}{|c|c|c|}
\hline$\nu_{\max }\left(\mathrm{cm}^{-1}\right)$ Tentative assignment ${ }^{\mathrm{a}}[12]$ & $\Delta \nu_{1 / 2}\left(\mathrm{~cm}^{-1}\right)$ & $\tau_{\text {SERS }}(\mathrm{ps})$ \\
\hline \multicolumn{3}{|l|}{ Florina } \\
\hline 567 & 23 & 0.46 \\
\hline 611 & 15 & 0.71 \\
\hline \multicolumn{3}{|l|}{ Romus 4} \\
\hline 611.5 & 14.5 & 0.73 \\
\hline $772(\mathrm{dC})$ & 24 & 0.44 \\
\hline 930 (Deoxyribose) & 23 & 0.46 \\
\hline $1128(\mathrm{dA})$ & 18 & 0.59 \\
\hline 1180 (Ring vibrations of dG, dT, dC) & 23 & 0.46 \\
\hline \multicolumn{3}{|l|}{ Romus 3} \\
\hline 612 & 16 & 0.66 \\
\hline $773(\mathrm{dC})$ & 21 & 0.51 \\
\hline 929 (Deoxyribose) & 19 & 0.56 \\
\hline $1087\left(\mathrm{PO}_{2}{ }^{-}\right.$symmetric stretch, bk $\left.{ }^{\mathrm{b}}\right)$ & 18 & 0.59 \\
\hline $1127(\mathrm{dA})$ & 19 & 0.56 \\
\hline 1181 (Ring vibrations of dG, dT, dC) & 22 & 0.48 \\
\hline $1311(\mathrm{dA})$ & 19.5 & 0.54 \\
\hline $1362(\mathrm{dT}, \mathrm{dA})$ & 15 & 0.71 \\
\hline $1510(\mathrm{dA})$ & 21 & 0.51 \\
\hline $1573(\mathrm{dG}, \mathrm{dA})$ & 18 & 0.59 \\
\hline $1650\left[\mathrm{dT}(\mathrm{C}=\mathrm{O}), \delta\left(\mathrm{H}_{2} \mathrm{O}\right)\right]$ & 20 & 0.53 \\
\hline \multicolumn{3}{|l|}{ Rebra } \\
\hline 611 & 15 & 0.71 \\
\hline $773(\mathrm{dC})$ & 21 & 0.51 \\
\hline 928 (Deoxyribose) & 20 & 0.53 \\
\hline $1128(\mathrm{dA})$ & 17.5 & 0.61 \\
\hline 1181 (Ring vibrations of dG, dT, dC) & 23 & 0.46 \\
\hline $1311(\mathrm{dA})$ & 21 & 0.51 \\
\hline $1362(\mathrm{dT}, \mathrm{dA})$ & 19 & 0.56 \\
\hline $1510(\mathrm{dA})$ & 20 & 0.53 \\
\hline $1575(\mathrm{dG}, \mathrm{dA})$ & 23 & 0.46 \\
\hline $1649\left[\mathrm{dT}(\mathrm{C}=\mathrm{O}), \delta\left(\mathrm{H}_{2} \mathrm{O}\right)\right]$ & 20.5 & 0.52 \\
\hline \multicolumn{3}{|l|}{ Goldrush } \\
\hline 611 & 16 & 0.66 \\
\hline $772(\mathrm{dC})$ & 22 & 0.48 \\
\hline $1129(\mathrm{dA})$ & 17 & 0.62 \\
\hline $1362(\mathrm{dT}, \mathrm{dA})$ & 20 & 0.53 \\
\hline $1510(\mathrm{dA})$ & 20 & 0.53 \\
\hline $1650\left[\mathrm{dT}(\mathrm{C}=\mathrm{O}), \delta\left(\mathrm{H}_{2} \mathrm{O}\right)\right]$ & 19.5 & 0.54 \\
\hline
\end{tabular}

Notes: Data correspond to the same samples as in Table 1, but at a time later on. ${ }^{\mathrm{a}}$ Abbreviations: $\mathrm{dA}$ - deoxyadenosine; $\mathrm{dG}$ - deoxyguanosine; $\mathrm{dC}$ - deoxycytidine; $\mathrm{dT}$ - deoxythymidine. ${ }^{\mathrm{b}} \mathrm{bk}$ - backbone. 
Besides, the bandwidths of the SERS vibrations around $773 \mathrm{~cm}^{-1}, 929 \mathrm{~cm}^{-1}, 1087 \mathrm{~cm}^{-1}, 1127 \mathrm{~cm}^{-1}$, $1181 \mathrm{~cm}^{-1}, 1311 \mathrm{~cm}^{-1}, 1362 \mathrm{~cm}^{-1}, 1510 \mathrm{~cm}^{-1}, 1573 \mathrm{~cm}^{-1}$ and $1650 \mathrm{~cm}^{-1}$ (see Table 2) are sensitive to a dynamics active on a time scale from 0.44 to $0.71 \mathrm{ps}$.

For the cases of overlapped Raman profiles, only half of the total half bandwidth (FWHM), in the side where the bands were not superposed, was taken into account and later on this was multiplied by two.

Based on the vibration near $1550 \mathrm{~cm}^{-1}$ (Table 1), which is a superposition of bands, we can conclude that a simultaneous molecular dynamics of the two DNA constituents ( $\mathrm{dG}, \mathrm{dA})$ takes place.

We will analyze in the followings, data in Table 1.

The global relaxation time of the band near $757 \mathrm{~cm}^{-1}(\mathrm{dT})$ is in the range of $0.31-0.48 \mathrm{ps}$. The limit values of this interval belong to Goldrush DNA $(0.31 \mathrm{ps})$ and to Florina DNA, respectively ( $0.48 \mathrm{ps})$.

Referring to the $\mathrm{dC}$ residues vibration at $772 \mathrm{~cm}^{-1}$ the vibrational energy transfer processes are characterized by global relaxation times between $0.37-0.45$ ps. The smallest global relaxation time was found for DNA of Romus 4, in the case of this band.

The global relaxation time of the band at $1126 \mathrm{~cm}^{-1}(\mathrm{dA})$ varied between 0.54 and $0.76 \mathrm{ps}$. The fastest dynamics of this band was found for DNA of Romus 3 and the slowest dynamics was detected in the case of Goldrush DNA.

Slow molecular relaxation processes have also been observed previously by us for the FT-Raman band of dA at $1124 \mathrm{~cm}^{-1}$ in the case of sword fern (global relaxation time $1.09 \mathrm{ps}$ ) and common sundew (global relaxation time $1.04 \mathrm{ps}$ ), respectively [9]. We have found, that the molecular relaxation processes are the slowest for the dA residues, as compared to those of all the other DNA molecular subgroups [7, $9,10]$.

As far as present work is concerned, we have established a global relaxation time of 0.45 ps for the profile near $1179 \mathrm{~cm}^{-1}$ (ring vibrations of $\mathrm{dG}, \mathrm{dT}, \mathrm{dC}$ ), in the case of Rebra cultivar.

Identical values of the SERS global relaxation times have been obtained for the band at $1361 \mathrm{~cm}^{-1}$ (dT, dA), in the case of genomic DNAs isolated from Romus 3 and Rebra leaf tissues, respectively (0.51 ps).

The global relaxation time of the band near $1511 \mathrm{~cm}^{-1}(\mathrm{dA})$ is in the range of $0.35-0.44 \mathrm{ps}$. The fastest dynamics of this band was detected for Romus 4 (global relaxation time $0.35 \mathrm{ps)}$ ) and the slowest dynamics was observed for Romus 3 and Rebra cultivars, respectively (identical global relaxation time 0.44 ps) (see Table 1).

In our study, the best vibrational energy transfer process was obtained for the $\mathrm{dG}, \mathrm{dA}$ band at $1550 \mathrm{~cm}^{-1}$ in the case of DNA extracted from Florina cultivar (global relaxation time $0.20 \mathrm{ps}$ ).

Besides, a slower dynamics has been found by us for the band near $1651 \mathrm{~cm}^{-1}\left[\mathrm{dT}(\mathrm{C}=\mathrm{O}), \delta\left(\mathrm{H}_{2} \mathrm{O}\right)\right]$, in the case of DNA extracted from Rebra (global relaxation time $0.59 \mathrm{ps}$ ) and from Romus 3, respectively (global relaxation time $0.48 \mathrm{ps}$ ).

For the case of genomic DNAs from Rebra, Romus 3 and Romus 4, respectively, the vibration near $1511 \mathrm{~cm}^{-1}(\mathrm{dA})$ corresponds to the fastest dynamics, as compared to all the other analyzed structural groups. In the case of DNA from Rebra cultivar, the global relaxation times corresponding to the bands near 1511 and $772 \mathrm{~cm}^{-1}(\mathrm{dC})$ are identical $(0.44 \mathrm{ps})$.

We will also discuss data in Table 2, in the next paragraphs.

The global relaxation time characterizing the band near $772 \mathrm{~cm}^{-1}(\mathrm{dC})$ varied between $0.44-0.51 \mathrm{ps}$. The maximum value, corresponding to the slowest relaxation processes belongs to the SERS band of Romus 3 and Rebra DNA, respectively. The smallest global relaxation time and the largest half bandwidth, respectively, have been detected for the SERS band at $772 \mathrm{~cm}^{-1}$, in the case of DNA extracted from Romus 4. 
Referring to the deoxyribose vibration near $929 \mathrm{~cm}^{-1}$ the vibrational energy transfer processes are characterized by global relaxation times ranging between 0.46 and $0.56 \mathrm{ps}$. The smallest global relaxation time was found for Romus 4 DNA, in the case of this band. The slowest dynamics characterizing this profile was found for Romus 3 DNA.

We have established a global relaxation time of $0.59 \mathrm{ps}$ for the profile near $1087 \mathrm{~cm}^{-1}\left(\mathrm{PO}_{2}{ }^{-}\right.$symmetric stretch, backbone), in the case of DNA extracted from Romus 3 cultivar.

The global relaxation time of the band near $1128 \mathrm{~cm}^{-1}(\mathrm{dA})$ varied between $0.56-0.62 \mathrm{ps}$. The fastest dynamics of this band was found for Romus 3 DNA and the slowest dynamics was detected in the case of Goldrush DNA, the same like in the case of data presented in Table 1. This band shifts to higher wavenumbers as compared to the results presented by us in Table 1 .

Identical values of the SERS global relaxation times have been obtained by us for the band at $1181 \mathrm{~cm}^{-1}$ (ring vibrations of $\mathrm{dG}, \mathrm{dT}, \mathrm{dC}$ ), in the case of genomic DNAs isolated from Romus 4 and Rebra leaf tissues, respectively ( $0.46 \mathrm{ps})$. In the case of Romus 3 DNA, a 0.48 ps global relaxation time has been found. As an observation, molecular relaxation processes of this band do not change too much with respect to the cultivar of the apple plants.

The dA band profile near $1311 \mathrm{~cm}^{-1}$ is characterized by global relaxation times of $0.54 \mathrm{ps}$, in the case of Romus 3 and of $0.51 \mathrm{ps}$, in the case of Rebra, respectively.

The global relaxation time of the SERS band near $1362 \mathrm{~cm}^{-1}(\mathrm{dT}, \mathrm{dA})$, is in the range of $0.53-0.71 \mathrm{ps}$. The limit values of this interval belong to Goldrush DNA ( $0.53 \mathrm{ps})$ and to Romus 3 DNA, respectively (0.71 ps).

In our study, the vibrational energy transfer processes obtained for the dA band at $1510 \mathrm{~cm}^{-1}$ are identical in the case of DNA extracted from Rebra and Goldrush cultivars (global relaxation times $0.53 \mathrm{ps}$ ) and much alike for DNA from Romus 3 (global relaxation time $0.51 \mathrm{ps}$ ). Like in the case of profile at $1181 \mathrm{~cm}^{-1}$, subpicosecond dynamics of this band do not change too much with respect to the cultivar of the apple leaf tissues.

As far as the band near $1575 \mathrm{~cm}^{-1}(\mathrm{dG}, \mathrm{dA})$ is concerned, the fastest dynamics was detected for DNA from Rebra cultivar (global relaxation time $0.46 \mathrm{ps}$ ) and the slowest dynamics was observed for DNA from Romus 3 (global relaxation time $0.59 \mathrm{ps}$ ).

Besides, vibrational energy transfer processes characterized by global relaxation times between 0.52 and $0.54 \mathrm{ps}$ have been found by us for the band near $1650 \mathrm{~cm}^{-1}\left[\mathrm{dT}(\mathrm{C}=\mathrm{O}), \delta\left(\mathrm{H}_{2} \mathrm{O}\right)\right]$, in the case of DNA extracted from Rebra (global relaxation time $0.52 \mathrm{ps}$ ), from Romus 3 (global relaxation time $0.53 \mathrm{ps}$ ) and from Goldrush, respectively (global relaxation time $0.54 \mathrm{ps}$ ).

In our study, the bands near 1181,1510 and $1650 \mathrm{~cm}^{-1}$ are the most stable with respect to the type of genomic DNA extracted from apple leaf tissues, as far as molecular dynamics is concerned.

As a general observation, the number of the SERS markers characteristic to $\mathrm{dA}, \mathrm{dG}, \mathrm{dC}$ and $\mathrm{dT}$ residues, for which FWHM and global relaxation times have been established, increased in the case presented in Table 2, as compared with that in Table 1 (it is not the case of Florina cultivar). Besides, dynamic parameters attributed to the deoxyribose band near $929 \mathrm{~cm}^{-1}$ could be determined for some particular plant DNAs.

In general, the full widths at half-maximum (FWHM) of the SERS bands in genomic DNAs presented here, decrease with the increase of the interaction time between the aqueous solution of nucleic acids and the SERS silver colloidal substrate, while the global relaxation times of the molecular subgroups, increase (dynamics is slower). Concerning to this, there are some exceptions, e.g., band near $1575 \mathrm{~cm}^{-1}$ $(\mathrm{dG}, \mathrm{dA})$ of DNA from Rebra and band near $1129 \mathrm{~cm}^{-1}(\mathrm{dA})$ of DNA from Goldrush. 
Table 3

Comparison between different ranges of the Raman band parameters, in the case of aqueous solution dynamics (FT-Raman) and surface dynamics (SERS) of DNA extracted from leaf tissues

\begin{tabular}{lcc}
\hline DNA molecules & $\begin{array}{c}\text { FWHM range } \\
\Delta \nu\left(\mathrm{cm}^{-1}\right)\end{array}$ & $\begin{array}{c}\text { Global relaxation } \\
\text { time range } \tau(\mathrm{ps})\end{array}$ \\
\hline Genomic DNA from in vitro-grown plant species, FT-Raman study & $7.8-23.1$ & $0.46-1.36$ \\
Genomic DNA from in vitro-grown apple plants, SERS study, time 1 & $14-52$ & $0.20-0.76$ \\
Genomic DNA from in vitro-grown apple plants, SERS study, time 2 & $14.5-23$ & $0.46-0.73$ \\
\hline
\end{tabular}

In the second case (data presented in Table 2), we do not have overlapping bands leading to high FWHMs (e.g., 30, $52 \mathrm{~cm}^{-1}$ as in Table 1).

As a general observation, the upper limit of the SERS global relaxation times variation interval remains almost constant with the increase of interaction time between the aqueous solution of nucleic acids and the silver colloid, while the lower limit increases.

We have found that the bands of DNA from Romus 3 and Rebra cultivars, respectively, are suitable for the study of dynamical behaviour of molecular subgroups in nucleic acids extracted from in vitro-grown apple leaf tissues (see Tables 1 and 2).

Besides, a comparison between different ranges of the Raman band parameters, in the case of aqueous solution dynamics (FT-Raman) and surface dynamics (SERS) of DNA extracted from leaves, is given in Table 3 .

The surface dynamics of plant DNA is more rapid than the solution dynamics of nucleic acids from leaf tissues, that is mobility is greater even in the case of interaction with a surface. An explanation of this observation might be, that in solution are possible to be present molecular associations, solvent interactions, etc., leading to a slower dynamics (a slower mobility). On the surface, the clusters are broken and DNA is interacting only with the surface, having a higher mobility. Particularly, bands at $1087 \mathrm{~cm}^{-1}\left(\mathrm{PO}_{2}{ }^{-}\right.$symmetric stretch, backbone) and $1126 \mathrm{~cm}^{-1}(\mathrm{dA})$, in the case of FT-Raman and SERS spectra of plant DNA, respectively, have been compared $[9,11]$.

\section{Conclusions}

We have shown that surface-enhanced Raman scattering can be used to study the fast subpicosecond dynamics of DNA in the proximity of a metallic surface.

This work presents a surface-enhanced Raman spectroscopic study into the vibrational total half bandwidths of molecular subgroups in five genomic DNAs from in vitro-grown apple leaf tissues (Malus domestica Borkh., Fam Rosaceae, cvs. Florina, Rebra, Goldrush, Romus 3 and Romus 4). Besides, the corresponding global relaxation times have been derived. An example of the time-dependence of the DNA band parameters, in the proximity of silver nanoparticles have been given.

SERS band parameters were obtained for the vibrational modes at $757 \mathrm{~cm}^{-1}(\mathrm{dT}), 773 \mathrm{~cm}^{-1}(\mathrm{dC})$, $929 \mathrm{~cm}^{-1}$ (deoxyribose), $1087 \mathrm{~cm}^{-1}\left(\mathrm{PO}_{2}{ }^{-}\right.$symmetric stretch, backbone), $1127 \mathrm{~cm}^{-1}(\mathrm{dA}), 1181 \mathrm{~cm}^{-1}$ (ring vibrations of $\mathrm{dG}, \mathrm{dT}, \mathrm{dC}), 1311 \mathrm{~cm}^{-1}(\mathrm{dA}), 1362 \mathrm{~cm}^{-1}(\mathrm{dT}, \mathrm{dA}), 1510 \mathrm{~cm}^{-1}(\mathrm{dA}), 1573 \mathrm{~cm}^{-1}$ $(\mathrm{dG}, \mathrm{dA})$ and $1650 \mathrm{~cm}^{-1}\left[\mathrm{dT}(\mathrm{C}=\mathrm{O}), \delta\left(\mathrm{H}_{2} \mathrm{O}\right)\right]$, characteristic to genomic DNAs from different apple leaf tissues [12]. It has been shown, that changes in the subpicosecond dynamics of molecular subgroups in genomic DNAs from in vitro-grown apple leaf tissues, can be monitored with surface-enhanced Raman spectroscopy. 
The study of vibrational total half bandwidths of genomic DNA from apple leaf tissues, revealed a sensitivity of FWHM to the source of nucleic acid. Moreover, this proved to be dependent on the vibration under study. The SERS total half bandwidths of genomic DNA vibrations revealed a dynamic picture on a subpicosecond time scale. Full widths at half-maximum (FWHM) of the bands in genomic DNA from in vitro-grown apple leaf tissues are typically in the wavenumber range from 14 to $52 \mathrm{~cm}^{-1}$. The total half bandwidths in the SERS spectra are sensitive to a dynamics active on a time scale from 0.20 to $0.76 \mathrm{ps}$.

The fastest and the slowest relaxation processes for some DNA vibrations, have been indicated.

We have found, that the bands of DNA from Romus 3 and Rebra cultivars, respectively, are suitable for the study of dynamical behaviour of molecular subgroups, in nucleic acids extracted from in vitro-grown apple plants.

A comparison between different ranges of the Raman band parameters of plant genomic DNA, in the case of aqueous solution dynamics (investigated by FT-Raman spectroscopy) and surface dynamics (investigated by SERS) has been given.

\section{Acknowledgements}

The authors wish to thank to Dr. Adela Halmagyi and to Dr. Sergiu Valimareanu from the Institute of Biological Research, Cluj-Napoca, Romania, for preparation of genomic DNAs from in vitro-grown apple leaf tissues.

\section{References}

[1] A. Hernanz, I. Bratu and R. Navarro, J. Phys. Chem. B 108(7) (2004), 2438-2444.

[2] A. Hernanz, I. Bratu, R. Navarro, J.P. Huvenne and P. Legrand, J. Chem. Soc. Faraday Trans. 92(7) (1996), 1111-1115.

[3] T. Iliescu, S. Aştilean, I. Bratu, R. Grecu and D. Maniu, J. Chem. Soc., Faraday Trans. 92 (1996), 175-178.

[4] T. Iliescu, I. Bratu, R. Grecu, T. Veres and D. Maniu, J. Raman Spectrosc. 25 (1994), 403-407.

[5] V. Kozich, Ł. Szyc, E.T.J. Nibbering, W. Werncke and T. Elsaesser, Chem. Phys. Lett. 473 (2009), 171-175.

[6] C.M. Muntean and I. Bratu, Spectroscopy - An International Journal 21(4) (2007), 193-204.

[7] C.M. Muntean and I. Bratu, Spectroscopy - An International Journal 22(5) (2008), 345-359.

[8] C.M. Muntean and I. Bratu, Spectroscopy - An International Journal 22(6) (2008), 475-489.

[9] C.M. Muntean and I. Bratu, Spectroscopy - An International Journal 23(5,6) (2009), 281-289.

[10] C.M. Muntean, I. Bratu, K. Nalpantidis and M.A.P. Purcaru, Spectroscopy - An International Journal 23(3,4) $(2009)$, $141-154$

[11] C.M. Muntean, A. Halmagyi, M.D. Puia and I. Pavel, Spectroscopy - An International Journal 23(2) (2009), 59-70.

[12] C.M. Muntean, N. Leopold, A. Halmagyi and S. Valimareanu, Journal of Raman Spectroscopy 42(4) (2011), 844-850.

[13] C.M. Muntean, R. Misselwitz, L. Dostál and H. Welfle, Spectroscopy - An International Journal 20(1) (2006), 29-35.

[14] C.M. Muntean, R. Misselwitz and H. Welfle, Spectroscopy - An International Journal 20(5,6) (2006), $261-268$.

[15] C. Otto, P.A. Terpstra and J. Greve, in: Fifth International Conference on the Spectroscopy of Biological Molecules, T. Theophanides et al., eds, Kluwer, Dordrecht, 1993, pp. 55-58.

[16] C. Otto, P.A. Terpstra, G.M.J. Segers-Nolten and J. Greve, in: Spectroscopy of Biological Molecules, J.C. Merlin et al., eds, Kluwer, Dordrecht, 1995, pp. 313-314.

[17] A.V. Rakov, Optika i Spektrosk. 7 (1959), 202-208.

[18] W. Saenger, Principles of Nucleic Acid Structure, C.R. Cantor, ed., Springer-Verlag, New York, 1984, p. 81.

[19] P.A. Terpstra, C. Otto and J. Greve, Biopolymers 41(7) (1997), 751-763.

[20] S. Woutersen, Y. Mu, G. Stock and P. Hamm, PNAS 98(20) (2001), 11254-11258. 


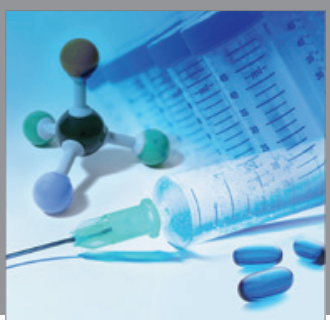

International Journal of

Medicinal Chemistry

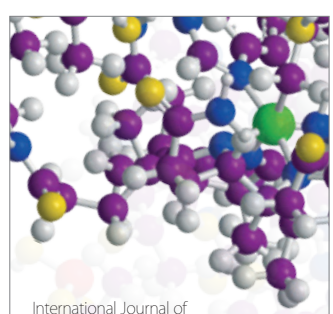

Carbohydrate Chemistry

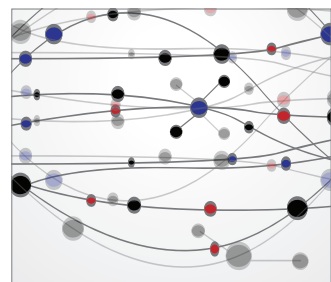

The Scientific World Journal
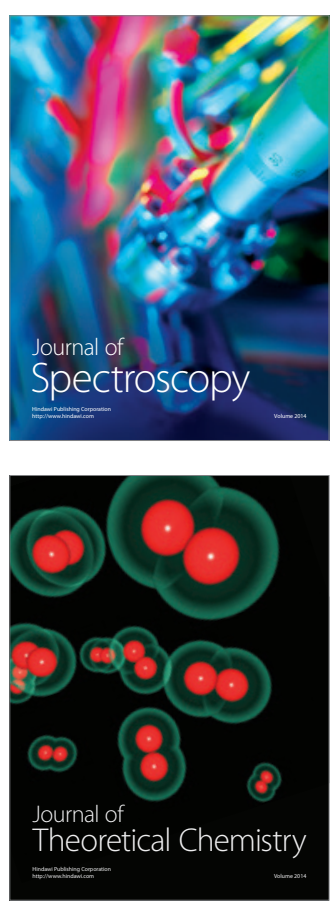
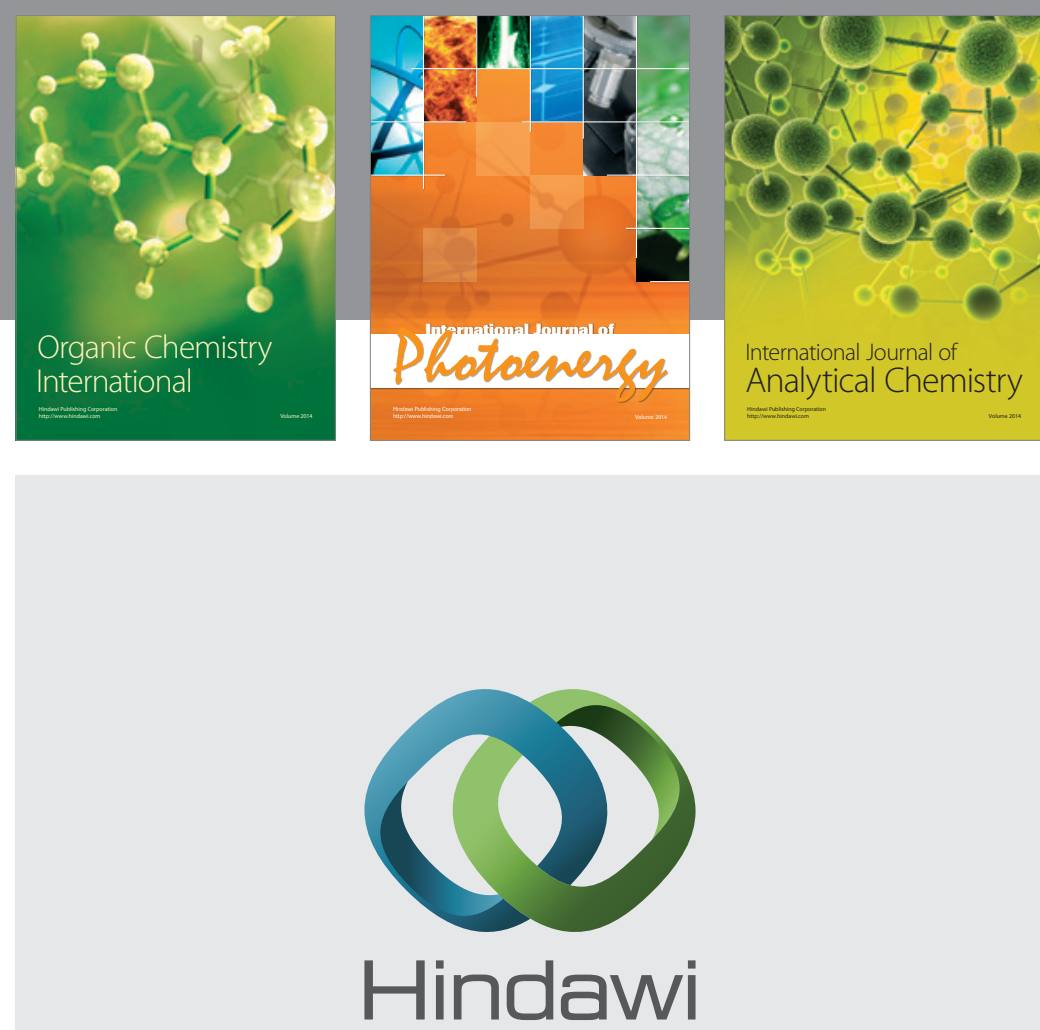

Submit your manuscripts at

http://www.hindawi.com
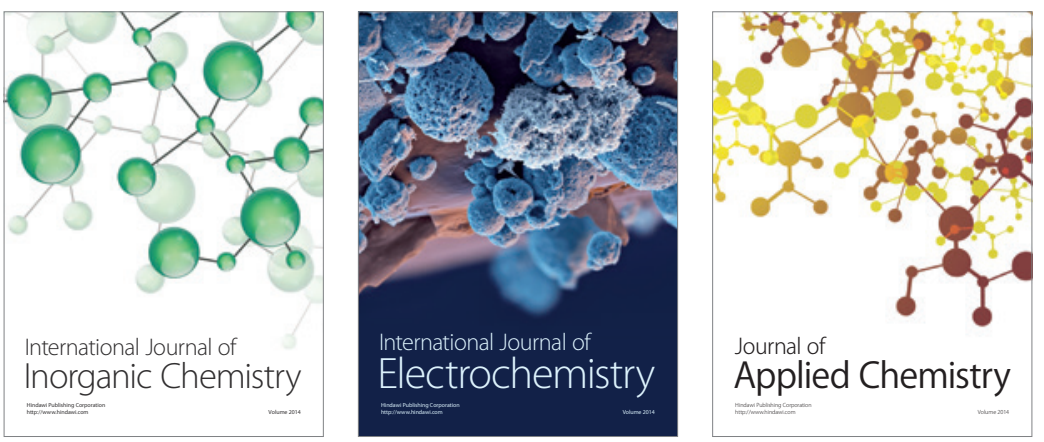

Journal of

Applied Chemistry
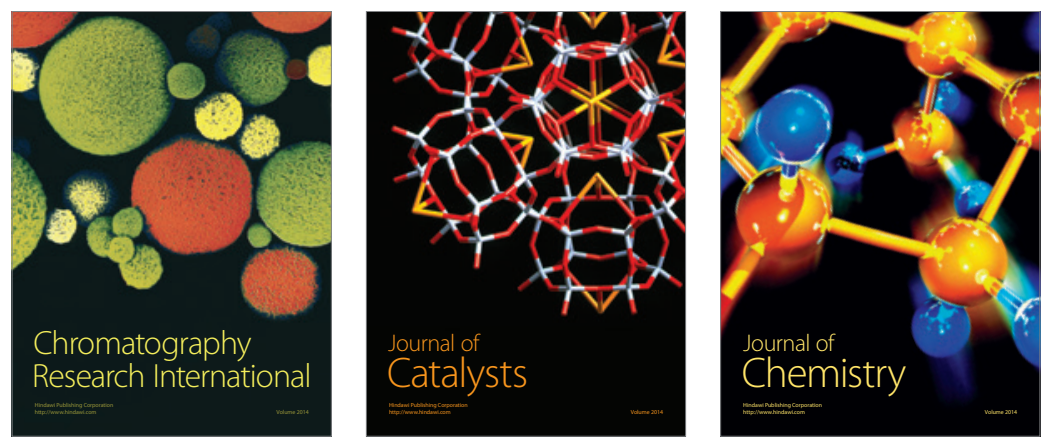
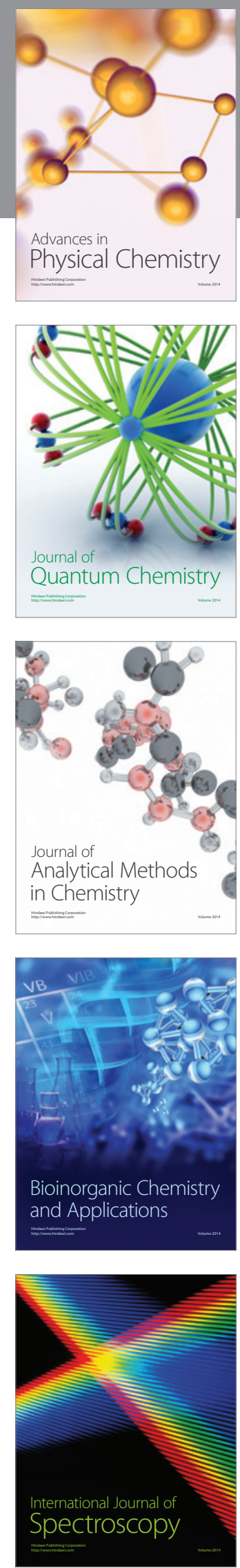